\title{
Abocats a viure a la llera del riu: el problema de l'infrahabitatge a Sabadell, 1939-1970. De l'habitatge protegit al negoci immobiliari*
}

\author{
Eduard Masjuan
}

Universitat de Barcelona. Departament d'Història i Institucions Econòmiques masjuan@ub.edu

Recepció: agost de 2013 Acceptació: abril de 2014

A la memòria de Manuel Ribas Piera

\section{Resum}

En aquesta recerca es pretén mostrar com el dèficit crònic d'habitatge en una ciutat industrial com Sabadell de 1939 a 1970 tingué en les riuades de 1962 el motiu per consolidar les patologies del creixement desregulat dels anys anteriors, i aprofundir així en un model urbà invertebrat que donarà lloc a una difusió suburbial dins la periferia de Barcelona. Es mostra com els poders econòmics de l'època franquista supeditaren tot intent d'urbanisme al servei de les persones a l'especulació del sòl. L'actual ciutat de Sabadell de després del boom immobiliari recent seria l'hereva d'un passat que transità de l'activitat industrial cap al negoci immobiliari.

Les riuades de 1962, juntament amb el creixement ràpid i incontrolat de la població, són aprofitades pel paternalisme franquista local i foren la gran excusa per a la consecució hegemònica del règim de propietat, que va fer quedar en segon terme el de lloguer, una condició prèvia per a la hiperespecialització de la ciutat en el negoci de l'especulació immobiliària. Ess a partir del que anomena José Manuel Naredo (2010) años del desarrollismo, 1963-1973, que l'embranzida immobiliària representa un augment del 40\% de construcció d'habitatges a Espanya, amb el consegüent urbanisme salvatge, resultat d'aquest procés d'urbanització sense precedents.

* Aquest article és una adaptació de la conferència llegida dins el cicle «La Nit Tràgica», amb motiu dels 50 anys dels aiguats del Vallès, a Sabadell el dia 25 de setembre de 2012. Museu d'Història de Sabadell. Ajuntament de Sabadell. 
L'objectiu central d'aquest text és establir com, partint de l'excusa d'escassetat inicial d'habitatges - palesa en un primer moment en el barraquisme i el fenomen legal dels rellogats i en un moment de clara hegemonia del règim de lloguer-, el 1962 aquesta situació es comença a invertir per complet, per raons polítiques d'una banda, per aconseguir la pau social, i per una altra, econòmiques, per afavorir l'especulació immobiliària. Tot plegat fou possible a partir de neutralitzar els intents de planificació urbana sorgida a l'empara de la legalitat vigent, sobretot a partir de la Llei del sòl de 1956.

Paraules clau: aiguats del Vallès de 1962; habitatge protegit; especulació immobiliària; infrahabitatge i salari vital.

Resumen. Condenados a vivir en el lecho del río: el problema de la infravivienda en Sabadell, 1939-1970. De la vivienda social al negocio inmobiliario

En esta investigación se pretende mostrar cómo el déficit crónico de vivienda en una ciudad industrial como Sabadell de 1939 a 1970 tuvo en las riadas de 1962 el motivo para consolidar las patologías del crecimiento desregulado de los años anteriores, y profundizar así en un modelo urbano invertebrado que dará lugar a una difusión suburbial en la periferia de Barcelona. Se muestra cómo los poderes económicos de la época franquista supeditan todo intento de urbanismo al servicio de las personas a la especulación del suelo. La actual ciudad de Sabadell de después del boom inmobiliario reciente sería la heredera de un pasado que transitó de la actividad industrial hacia el negocio inmobiliario.

Las riadas de 1962, junto con el crecimiento rápido e incontrolado de la población, son aprovechadas por el paternalismo franquista local y fueron la gran excusa para la consecución hegemónica del régimen de propiedad, que hizo quedar en segundo término el de alquiler, una condición previa para la hiperespecialización de la ciudad en el negocio de la especulación inmobiliaria. Es a partir de lo que llama José Manuel Naredo (2010) años del desarrollismo, 1963-1973, que el empuje inmobiliario representa un aumento del $40 \%$ de construcción de viviendas en España, con el consiguiente urbanismo salvaje, resultado de este proceso de urbanización sin precedentes.

El objetivo central del texto es establecer cómo, partiendo de la excusa de escasez inicial de viviendas - patente en un primer momento en el barraquismo y el fenómeno legal de los realquilados y en un momento de clara hegemonía del régimen de alquiler-, en 1962 esta situación se empieza a invertir por completo, por razones políticas de un lado para conseguir la paz social, y por otro, económicas para favorecer la especulación inmobiliaria. Todo ello fue posible a partir de neutralizar los intentos de planeamiento urbano surgidos al amparo de la legalidad vigente, sobre todo a partir de la Ley del suelo de 1956.

Palabras clave: inundaciones del Vallès de 1962; vivienda protegida; especulación inmobiliaria; infravivienda y salario vital.

Résumé. Voués à vivre dans le lit du fleuve: le problème du logement indigne à Sabadell, 19391970. Du logement social à l'affaire immobilière

Cette recherche vise à montrer comment la pénurie chronique de logements dans une ville industrielle comme Sabadell de 1939 à 1970 a trouvé dans les inondations de 1962 le prétexte pour consolider les pathologies de croissance dérégulée des années précédentes, en développant ainsi un modèle urbain invertébré qui donnera lieu à une propagation de banlieue à la périphérie de Barcelone. On montrera la manière dont les forces économiques de la période franquiste ont subordonné à la spéculation du sol toute tentative d'urbanisme au service des personnes. L'actuelle ville de Sabadell, postérieure au boom immobilier, serait 
l'héritière d'un passé qui a vu la ville se tourner de l'activité industrielle vers les affaires immobilières.

Les inondations de 1962, avec une croissance démographique rapide et incontrôlée, ont été exploitées par le paternalisme franquiste local et ont été la grande excuse de la réalisation hégémonique du régime de propriété, la location passant au second plan, condition préalable à l'hyperspécialisation de ville dans l'affaire de la spéculation immobilière. À partir de ce que Jose Manuel Naredo (2010) appelle les années du "desarrollismo", de 1963 à 1973, la poussée immobilière représente une augmentation de quarante pour cent de la construction de logements en Espagne. Cette augmentation a provoqué un urbanisme sauvage, résultat d'un processus d'urbanisation sans précédent.

L'objectif principal du texte est d'établir la manière dont, partant du prétexte initial du manque de logements, évident dans un premier temps avec le "barraquismo» et le phénomène de sous-location et à un moment de nette domination du régime de location, à partir de 1962, cette situation a commencé à se renverser complètement pour des raisons politiques d'une part, afin d'obtenir la paix sociale, et économiques d'autre part, afin de promouvoir la spéculation immobilière. Tout ceci a été possible à partir de la neutralisation des tentatives de planifications urbaines qui ont vu le jour sous la protection de la législation en vigueur, surtout depuis la Loi du Sol de 1956.

Mots-clé: inondations du Vallès 1962; logements subventionnés; spéculation immobilière; logements insalubres et salaire vital.

Abstract. Doomed to live in the river: the problem of substandard real-estate in Sabadell, 1939-1970. From social housing to the real estate business

This research study aims to show how, in the context of the chronic shortage of real-estate in an industrial city like Sabadell from 1939 to 1970, the 1962 floods were the reason for consolidating the pathologies of unregulated growth of previous years. So, this is a detailed examination of an unregulated urban model that led to suburban sprawl on the outskirts of Barcelona. It shows how economic forces during the Franco regime caused any attempt at town-and-country planning to serve the people to be subjected to land speculation. The trend after the recent housing boom in the city of Sabadell is the legacy of a past that shifted from industrial activity to the real estate business.

The floods of 1962, together with the rapid and uncontrolled growth of the population, were exploited by local Francoist paternalism and were the great excuse for achieving a hegemonic regime with regard to the property system and the detriment of the rental system, a precondition for the over-specialization of the city in terms of real estate speculation. From what Jose Manuel Naredo (2010) called the "developmentism years", from 1963 to 1973, in which real-estate pressure represented a forty per cent increase in housing construction in Spain, the consequent of this unprecedented urbanisation process has been what is dubbed wild city planning.

The main objective of the text is to establish how the initial excuse of the housing shortage was obvious at first in the slums and the phenomenon of legal subletting at a time of clear dominance of the rental system. From 1962 onwards, this situation began to be completely reversed, for political reasons on the one hand, in order to achieve social peace, and to promote economic speculation on the other. All this was possible by neutralizing any attempt at urban planning covered by current legislation, especially following the 1956 Land Law.

Keywords: Vallès Floods 1962; subsidized housing; property speculation; sub-standard housing and vital wage. 


\section{Sumari}

Introducció Nivell de renda i habitatge obrer

Fatalitat vs. especulació urbanística

Qui són els damnificats dels aiguats a Sabadell

Política de l'habitatge protegit a l'Espanya franquista de 1945-1959 Immigració i habitatge a Sabadell L'explosió del desordre urbanístic (1940-1960)

L'activitat constructora de l'empresariat tèxtil sabadellenc

Habitatge, pobresa i desastre: unes relacions amagades?

Conclusions

Referències bibliogràfiques periferic

\section{Introducció}

Les riuades del Vallès de 1962 van donar lloc a una catàstrofe d'origen natural sense precedents pel que fa al nombre de víctimes i danys materials. Algunes fonts comptabilitzen 350 morts, 372 desapareguts i 235 ferits; altres calculen el nombre de víctimes mortals al voltant del miler. ${ }^{1}$ Les xifres exactes, però, són difícils de precisar donada la quantitat d'habitants al Vallès desapareguts $\mathrm{i}$ no censats i dels quals alguns cossos no es van arribar a recuperar.

El desastre tingué lloc en un moment de ràpid canvi demogràfic, econòmic i ambiental, iniciat a partir de l'any 1950 , que donà com a resultat un augment de les vulnerabilitats humanes de les poblacions del Vallès. Aquesta qüestió es troba present en totes aquelles societats que esdevenen emergents en raó d'un creixement econòmic que comporta una massiva transformació del medi físic i molt especialment dels entorns fluvials (Bevere i Enz, 2012). Així, lleres de rieres i rius són ocupades sovint sota la forma d'habitatges molt precaris per part, majoritàriament, de població pobra immigrada. En aquest context, un factor que tendeix a incrementar la magnitud del desastre ocasionat pels aiguats i altres fenòmens naturals extrems és la manca de recursos de prevenció (Federació Internacional de Societats de la Creu Roja i de la Mitja Lluna, 2013). En aquest sentit, cal esmentar que si bé en aquells moments no hi havia l'arsenal de mesures disponibles que hi ha en l'actualitat, sí que hi havia una certa regulació dels usos del sòl als espais fluvials. Fins i tot, es poden trobar mesures de prevenció dels entorns fluvials durant la Guerra Civil a la memòria de la Delegació dels Serveis Hidràulics del Pirineu Oriental, la qual està sota la direcció de l'hidrogeòleg anarquista Alberto Carsí.

Així doncs, la manca de recursos i les ocupacions humanes en les rieres i els terrenys no urbanitzables comporten l'augment de la vulnerabilitat, davant d'esdeveniments naturals cíclics; en el cas del Vallès, propis del clima medi-

1. Segons les dades estadístiques obtingudes per les Oficines de Coordinació de la Secció Femenina de FET i de les JONS emplaçades als ajuntaments donen la xifra de 617 víctimes mortals per al conjunt de la província de Barcelona els dies 25 i 26 de setembre de 1962. 
terrani i amb un període de retorn estimat de cent anys. A tots aquests factors caldria afegir encara l'absència de xarxes cíviques ciutadanes o comunitàries capaces d'intervenir amb eficàcia sobre el terreny.

Aquest article se centrarà en alguns dels aspectes de vulnerabilitat esmentats i, més concretament, en l'anomenat "problema de la immigració» i el seu acompanyant: la manca d'habitatges accessibles per als treballadors industrials de Sabadell, aleshores en ple procés de creixement econòmic. L'objectiu del treball és situar en el context dels aiguats a Sabadell la resposta del poder econòmic i polític d'aleshores envers la problemàtica del dèficit crònic d'habitatge accessible per a la classe treballadora. Com sabem, tant a la comarca del Vallès Occidental com a la resta de la província de Barcelona de 1962 es donà un fort creixement econòmic amb força semblances amb el de molts dels nous països emergents de l'actualitat. En aquests països sovintegen catàstrofes naturals de gran magnitud, que es donen en un context sociopolític caracteritzat per règims escassament democràtics, com pot ser el cas xinès o el d'altres països.

Finalment, valorem de manera crítica les enormes responsabilitats que tingueren els poders econòmics i polítics de l'època en la catàstrofe del Vallès, els quals no es poden atribuir a la voluntat de Déu, com així es transmeté des de la premsa oficial. ${ }^{2}$ Ben al contrari, els precedents de la tragèdia es poden trobar en la política d'immigració i en l'especulació urbanística des de 1940 a la ciutat. També ens preguntem si les polítiques empresarials de sous i salaris, fins i tot per sota del nivell de subsistència adoptades durant el franquisme, repercutiren negativament a llarg termini en l'urbanisme de la ciutat així com en el seu futur productiu industrial.

El text s'organitza de la manera següent. Primer, s'analitza la política urbanística de Sabadell en dues etapes: la primera fins a 1960, caracteritzada per l'escassetat d'habitatge nou i en el context del moviment migratori, que provocà que el cinturó de Sabadell presentés una constel.lació de barraques, coves i infrahabitatges autoconstruïts, així com una forta densificació en infrahabitatges en el centre històric de la ciutat.

La segona etapa de la política urbanística a Sabadell arrenca a partir de 1957, quan es creà el Ministeri de l'Habitatge per tal d'abordar el problema de la manca d'habitatges entès pel poder polític franquista i pel poder econòmic de Sabadell com un problema d'ordre públic.

Els aiguats de 1962 al Vallès els situem en aquesta etapa de transició d'inici del «desarrollismo», amb la promoció d'habitatge en règim de propietat; per això analitzem la política urbanística de Sabadell duta a terme per l'àmbit empresarial, social $\mathrm{i}$ institucional davant les propostes de planificació urbana i territorial sota l'emparament de la Llei del sòl de 1956 pel que fa a la ciutat de Sabadell.

2. Així ho posà de manifest el bisbe de Terrassa Saiz Meneses el dia 30 de novembre de 2012 amb motiu de la inauguració del monòlit dedicat a les víctimes de Sabadell. Vegeu el Diari de Sabadell, de l'1 de desembre de 2012. 
La tragèdia humana i material ocasionada pels aiguats posà en evidència com el panorama immobiliari de Sabadell era el resultat d'un accentuat «laissez faire» que havia pervertit els objectius pels quals té raó de ser l'urbanisme: millorar les condicions de vida dels ciutadans a partir de millorar l'hàbitat urbà.

Definitivament, com es podrà comprovar al llarg del text, les recomanacions dels plans d'ordenació com el de la província de Barcelona foren impugnades pels poders econòmics i polítics de la ciutat. L'urbanisme de Sabadell acabà per servir exclusivament els interessos del creixent sector immobiliari, el qual acabarà sent el més dinàmic i gairebé exclusiu després de la mort de Franco i al llarg de tota la democràcia.

Les principals fonts documentades emprades al llarg de l'article provenen principalment dels fons existents al Gremi de Fabricants de Sabadell i de l'empresa Cooperativa de Viviendas Populares, S.A. (COVIPSA). Una altra de les fonts rellevants són els plans i les actuacions de l'Associació Catòlica de Dirigents de Sabadell. També són citades i altament valuoses les dades que es troben a les tesines inèdites de la primera generació d'assistents socials de Sabadell, les quals són considerades autèntics treballs de camp imprescindibles per a la recerca urbanística i social d'aquest període. Addicionalment s'han consultat les dades de l'habitatge construït a Sabadell de la memòria de 1943 a 1950, publicades per la Cambra Oficial de Comerç i Indústria de Sabadell.

\section{Fatalitat $v s$. especulació urbanística}

Com és sabut, els aiguats de 1962 provocaren víctimes mortals i destrucció al llarg de $900 \mathrm{~km}^{2}$, que van afectar barris sencers, infraestructura viària, logística, $\mathrm{i}$ indústries tèxtils i del ram de l'aigua.

Durant la nit del dia 25 de setembre s'enregistraren més de $200 \mathrm{l} / \mathrm{m}^{2}$ de precipitació en dues hores a les serres de l'Obac i Sant Llorenç del Munt. Aquestes precipitacions provocaren que a Terrassa, Les Fonts i Rubí, per la incidència de la riera de les Arenes, s'enregistrés el màxim de destrucció. A Sabadell es recolliren 257 litres per $\mathrm{m}^{2}$ i hora a les $21.41 \mathrm{~h} \mathrm{i} 361$ litres per $\mathrm{m}^{2}$ i hora a les $21.52 \mathrm{~h}^{3}$

Aquest aiguat, però, prengué la categoria de desastre gràcies a l'especulació de l'espai i del territori, sovint no urbanitzable, que tenia lloc a la periferia de la ciutat des de 1945, el qual requeia sobre la població obrera immigrada.

3. Aquest aiguat de característiques tropicals es degué a la conjunció del vent de llevant, molt calent i humit, amb un temporal de ponent d'aire fred. En iniciar-se la pluja en l'aire de llevant a causa de l'ascens de la serralada litoral, la calor desenvolupada per aquesta massa d'aire per causa de la condensació va produir la dilatació i l'ascens d'aquesta, la qual cosa implicà un augment de la velocitat de l'ascens. Així, una gran xemeneia d'aire calent ascendí pel mig de la massa d'aire fred, a una velocitat de $100 \mathrm{~km} / \mathrm{h}$, la qual va produir una precipitació de gran magnitud (A. P. Foriscot, 1963). Per a una descripció dels danys en diferents poblacions, vegeu Serra d'Or, 1962. 


\section{Qui són els damnificats dels aiguats a Sabadell}

En el cas de Sabadell, les víctimes dels aiguats són bàsicament població jove i immigrada en un $90 \%$. La mitjana d'edat de les víctimes és de 25 anys, seguida d'infants i vells. Algunes de les víctimes són treballadors joves que fan el torn de nit a les fabriques de la vora del Ripoll, juntament amb els habitants més vulnerables, com són els nens i els vells que viuen en barraques i semicases.

Ateses les qualitats dels habitatges de les víctimes mortals de Sabadell, es pot afirmar que els aiguats posaren de manifest l'especulació abusiva del sòl urbanitzable que des de 1945 es donava a la ciutat. Aquest problema havia estat afrontat per part de l'administració pública i dels poders econòmics de la ciutat des del liberalisme més ortodox, tot i que els salaris d'aquests treballadors nouvinguts no podien cobrir la despesa d'habitatge protegit. És per aquest fet que l'oferta d'habitatge no era considerada rendible, donada la situació de demanda insolvent d'aquesta població.

A tall d'exemple cal esmentar només que els peons del Vallès eren considerats els més mal pagats de tot l'Estat (Serra d'Or, 1962), ${ }^{4}$ amb un salari base que no superava les 36 ptes. diàries $[s i c]$. En un primer moment, a Sabadell 2.000 obrers quedaren sense feina.

El que crida l'atenció del gran nombre de damnificats a Sabadell és que no es limità als que vivien a la llera del riu Ripoll, ja que barris com Torre-romeu també resultaren greument afectats, amb l'efecte multiplicador produït per la pràctica d'allotjament de rellogats: pràctiques de cohabitació, com ara el relloguer i l'hostalatge, tant als barris periferics com en les estades del centre urbà.

Els que van perdre el seu habitatge foren allotjats temporalment a les escoles dels Merinals i a la Casa de Caritat, i la resta en altres habitatges cedits per particulars: masia de Can Borgunyó, albergs prefabricats de la Concòrdia, etc.

La magnitud de la catàstrofe fou, doncs, importantíssima i cal buscar-la en la configuració urbana de Sabadell de 1945 a 1962.

Òbviament, la catàstrofe provocada per les inundacions de 1962 no generà cap mena de protesta popular, en part gràcies a la propaganda oficial, que ho atribuí a un fet climàtic excepcional, acompanyat d'una ràpida resposta del govern de la dictadura - que va prometre que aquest desastre no es repetiriaa través d'indemnitzacions i préstecs a la indústria tèxtil de les ciutats afectades, especialment Sabadell i Terrassa. S'atorgaren 1.000 milions de pessetes en crèdits tous que avui encara es paguen i plans de polígons d'habitatges socials que posessin fi al dèficit crònic d'habitatges existent a Sabadell acompanyat del drenatge i encasament del riu Ripoll.

Amb tot, la tragèdia humana potser s'hagués pogut evitar si s'hagués seguit una planificació urbanística no basada en la ideologia corbuseriana del creixement urbà il.limitat com la que tenia el poder econòmic i polític local. Un urbanisme il.limitat que s'impulsava a Sabadell i a Barcelona des de $1930 \mathrm{amb}$

4. Informe sobre les inundacions de setembre. Serra d'Or, novembre de 1962, 2a època, any IV, núm. 11. 
el pla Macià, que entenia la plana del Vallès com una enorme reserva edificable connectada per autopistes i autovies amb la metròpoli barcelonina.

De moment, però, els damnificats de 1962 van ser majoritàriament les víctimes de la política d'habitatge de la primera etapa del franquisme, com tot seguit s'esmenta a través de la descripció de la panoràmica del mercat d'habitatge per a la massiva arribada d'immigrants a Sabadell.

\section{Política de l'habitatge protegit a l'Espanya franquista de 1945-1959}

El franquisme va considerar l'habitatge el primer problema nacional des de 1939 fins a 1954, període que es va necessitar per assolir els nivells d'edificació d'abans de la guerra en el conjunt català (Tafunell, 1989). En realitat, la política d'edificació del règim franquista només va aconseguir impulsar en el mateix període la meitat dels edificis construïts en els principals països d'Europa que s'hagueren de reconstruir després de la Segona Guerra Mundial. Aquest fracàs espanyol s'ha de buscar molt especialment en l'especulació immobiliària (a través de la forta revalorització del parc urbà existent) i també en l'escassetat de materials per a la construcció causada per la política econòmica autàrquica. L'activitat constructora quedava així reduïda a la demanda solvent i d'alt nivell, tal vegada que els recursos públics existents anaven destinats a la burgesia fidel al règim.

En el cas de Sabadell, com es recull en la memòria del Gremi de Fabricants de 1947, s'identifica que les vint persones que arriben per setmana a la ciutat aleshores no troben lloguers assequibles com a resultat dels pocs incentius remuneradors per a la construcció d'aquest tipus d'habitatge per als nous treballadors. A resultes del col-lapse en l'edificació d'habitatges per a treballadors, la ciutat començà a oferir un aspecte suburbial. Entenem per suburbi quelcom desagradable, depriment i desordenat en tres aspectes: creixement urbanístic, habitatge i serveis assistencials (Associació Catòlica de Dirigents, 1961). És a dir, la negació del concepte de ciutat. Al 1946 hi ha un total de 186 coves a tot Sabadell: 119 d'aquestes coves a la zona de Sant Oleguer, en un barranc format a banda i banda per bancs de terres arenoses al bell mig de les quals hi desembocava una de les clavegueres de la ciutat. El material del terreny resultava favorable a l'excavació de coves per part d'immigrants, procedents majoritàriament d'Andalusia i de Múrcia. Les terrasses que varen conformar, amb les seves corresponents fileres de coves i barraques, arribaren a tenir fins a tres pisos units per senders que servien de carrers. El paratge de Sant Oleguer s'ordenà definitivament, i pels seus propis habitants, per zones: «Aguas Sucias», Barranco Escombros, Barranco Cuadras i Can Cuadras (Masjuan, 2010).

És aleshores quan les institucions patronals de la ciutat comencen a veure amb preocupació l'increment de població nouvinguda empleada en la indústria local, davant la Llei publicada al BOE de 17 de juliol de 1946, la qual estipula en l'article primer les obligacions que tenen els empresaris que contracten més de 50 treballadors, respecte a l'allotjament d'aquests: 
Toda empresa individual o colectiva que proyecte la instalación de nuevas fábricas, talleres o explotación de cualquier índole, con carácter de permanencia, y en las que se hayan de emplear 50 o más productores, vendrá obligada a facilitar alojamiento familiar a su personal, cuando lo exija la estabilidad del número de productores y de los lugares de trabajo y para el acceso a éstos, no se disponga de medios de comunicación fáciles y debe realizarse a pie en distancias superiores a tres $\mathrm{km}$. Para el cumplimiento de esta obligación, las empresas afectadas podrán construir directamente el número de viviendas necesarias a concertar con la obra sindical del hogar o con las Diputaciones Provinciales o Ayuntamientos respectivos, la disponiblidad de tales viviendas (Boletín Oficial del Estado de 18 de julio de 1946).

Per als empresaris que s'acollissin a aquesta llei se'ls aplicaven les màximes bonificacions fiscals, avançaments del $40 \%$ del valor total del pressupost sense interès, preferència en l'adquisició de materials de construcció, així com facilitats per a l'expropiació forçosa de terrenys necessaris per a la construcció d'habitatges.

La llei d'abril de 1939 de protecció de l'habitatge de lloguer «reduït» i que creà per primera vegada a Espanya l'Instituto Nacional de la Vivienda (INV) per a tal finalitat, és ara ampliada per aquesta nova disposició esmentada, en la qual s'impliquen els àmbits privat i públic, però que no donà òbviament els resultats esperats per atendre el dèficit d'habitatge que comença a tenir lloc a les ciutats industrials.

Els resultats foren minsos, donada la insuficiència de materials de construcció, provocada per la limitació dels recursos financers posats a disposició de l'INV. Tot plegat fou resultat de la política econòmica intervencionista $\mathrm{i}$ autàrquica del règim. D'aquí es deriva el fracàs absolut de l'habitatge protegit l'Espanya d'aquells anys. S'estima que de 1944 a 1955 es van construir 112.105 habitatges d'aquest tipus a tot Espanya. D'aquests, el 36\% s'edificaren a les províncies de Madrid, de Santander i de Saragossa, que són les que absorbeixen el major nombre d'habitatges bonificables a tot Espanya. Cal remarcar que aquestes províncies no coincideixen amb les regions de més immigració (Cotorruelo, 1960).

A més, la Llei d'arrendaments urbans de desembre de 1946 permeté la congelació de lloguers i l'establiment de rendes màximes per als habitatges bonificables que fossin arrendats, davant la llibertat de preu en cas de venda. Aquest fet comportà que els habitatges es construïssin pensant a posar-los a la venda en condicions avantatjoses perquè fossin adquirits per famílies en una situació econòmica mitjana. Per tant, una part dels recursos per a l'habitatge protegit es destinaren a la construcció d'habitatges de semiluxe, per a les classes socials d'elevat poder adquisitiu de l'època. Tal vegada els empresaris que les construïren obtenien guanys gràcies a les subvencions públiques. Aquesta situació durà fins a 1954, quan s'estima que a tot Espanya només s'havia construït un 40\% del total previst (Cotorruelo, 1960).

D'aquesta manera el problema de la manca d'habitatge i la carestia d'aquest, requeia majoritàriament sobre la població nouvinguda en forma d'allotjament 
insalubre i precari, com així es reconeix en el primer cens municipal de coves i barraques fet públic l'any 1955 per la Delegació Municipal de Suburbis, el qual tot seguit analitzem.

\section{Immigració i habitatge a Sabadell}

L'any 1950, un primer cens de l'infrahabitatge a Sabadell ja mostra un gran increment d'aquest com a resultat dels baixos salaris vigents, de la recuperació del creixement vegetatiu autòcton i de l'arribada constant d'immigrants.

A la ciutat es posa de manifest que els treballadors amb una renda més baixa no es podien permetre una mínima despesa en habitatge, i no els quedava més solució que allotjar-se en cases d'autoconstrucció, estades, barraques i coves. La Comissió Superior d'Ordenació Provincial de Barcelona quantifica a Sabadell 354 cases, 70 semicases, 292 coberts habitats, 94 barraques i 182 coves en diversos nuclis periferics de la ciutat (E. Masjuan, 2010).

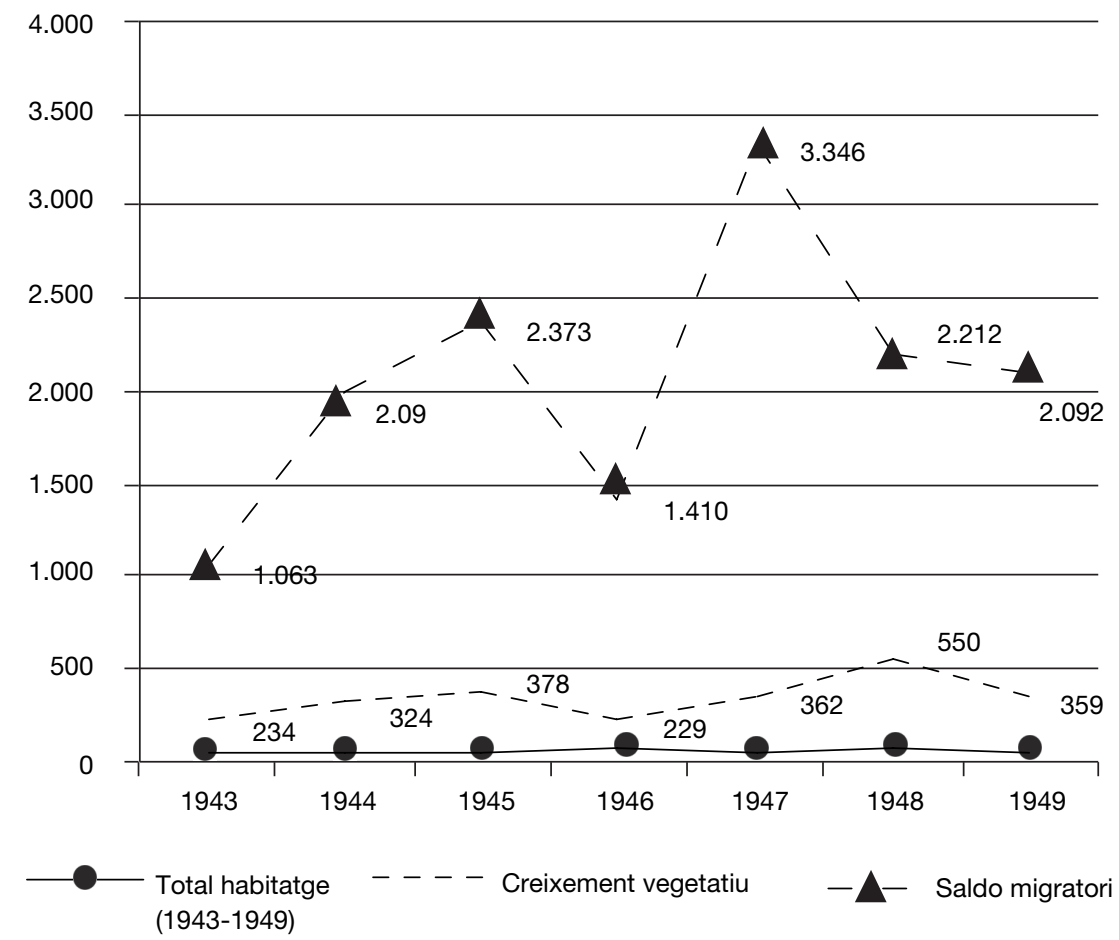

Gràfic 1. Evolució del creixement vegetatiu, el saldo migratori i el total d'habitatge construït a Sabadell entre 1943 i 1949.

Font: Cambra Oficial de Comerç i Indústria de Sabadell. Memòria de 1950 i elaboració pròpia. 
El paratge de Sant Oleguer, al sud-est de Sabadell, fou un dels sectors amb més proliferació de coves de la ciutat des de 1944. Per aquestes mateixes dates, els immigrants més pobres també s'allotjaren en coves en altres indrets de la ciutat al llarg del riu Ripoll, a la zona de la Llanera, Can Puiggener, Taulí i la Cobertera. Tot plegat arribà a formar un cinyell de coves i de barraques adossades al nucli urbà de la ciutat en forma de suburbi, que representà un vertader continu urbà a tots els efectes en forma d'infrahabitatges d'emergència.

El mateix poder polític franquista de la ciutat, culpabilitzà inicialment aquesta immigració «massiva» del creixent problema de l' habitatge. En aquest sentit, l'Alcaldia ordenà al 1947 que els 147 habitants de les 38 coves les abandonessin, i des d'aquell moment es procedeixen a enumerar (Masjuan, 2010).

Malgrat aquestes i altres mesures dissuasives es calcula que al 1953, en el moment de més dèficit d'habitatges per a la població immigrant pobra, arribaren a haver-hi al voltant de quatre-centes coves i barraques al marge dret del riu Ripoll, habitades gairebé per unes dues mil persones. Només a les coves de Sant Oleguer s'estima que l'any 1952 hi poden residir unes 1.500 persones (Sabadell, 17 d'abril de 1952, 5).

Al llarg de la primera meitat dels anys 1950 les esperances per trobar una solució al problema de l'habitatge obrer van passar pel pla de l'alcalde empresari Marcet de 1952 (Plan Marcet de la Vivienda). Aleshores és quan es creà l'anomenada Junta ciudadana para la construcción de Viviendas en Sabadell, integrada pels industrials i pels financers més importants de la ciutat en aquell moment. Marcet, com el mateix Franco, que havia fet un discurs a la localitat basca de Pasajes en aquelles dates comparant els obrers amb animals de tir que també necessiten estables, increpà en el seu discurs els empresaris locals amb aquest qüestionament: «Es que alguno de nosotros tiene sus camiones al aire libre y a las inclemencias del tiempo? ¿Podemos decir lo mismo de nuestros obreros y de sus famílias?» (J. M. Marcet, 1952).

De tot plegat en resultà un pla de construcció en el termini de dos anys, de 2.000 habitatges.

La viabilitat econòmica del pla es basava en una contribució directa en relació amb el nombre de treballadors immigrants que els empresaris locals tenien en nòmina. Aquest pla, excepte en el cas del mateix Marcet (pisos i cases a Can Marcet) i de Garcia Planas (barri de Nostra Llar de Sant Oleguer), no anirà més enllà i el problema de l'habitatge restarà per resoldre fins que les morts per esfondraments de juliol de 1953 a les coves de Sant Oleguer impulsin la Caixa d'Estalvis de Sabadell a oferir terrenys per revendre a preu de cost als habitants de les coves i de barraques de l'indret. A les pluges de tardor d'octubre de 1951 i setembre de 1953 ja s'havien enregistrat esfondraments de coves (aleshores n'hi havia unes 500), amb múltiples ferits de consideració. La catàstrofe en aquests casos, quan era possible, va ser evitada perquè, amb previsió, els habitants de les coves eren allotjats temporalment a la caserna de la Guàrdia Civil.

L'any 1955, com que els enfonsaments de coves continuaven en època de pluges, des de l'Ajuntament de Sabadell es creà la "Delegación de Suburbios", que va elaborar una estadística de la situació econòmica dels habitants de les 
coves i va procedir a ordenar les sol.licituds de compra d'habitatges anomenats «ultrabarats», majoritàriament per als habitants de les coves de Sant Oleguer, el suburbi més precari de la ciutat l'any 1958 que es va poder clausurar definitivament (Masjuan, 2010).

Aleshores, la població de Sabadell havia evolucionat de manera espectacular i sense precedents històrics. L'any 1963, el 54\% del total de la població de la ciutat vivia als suburbis, mentre que el 1945 aquesta població només era el $4 \%$ de la total.

Els mapes que es presenten a continuació mostren el procés d'urbanització dels suburbis a Sabadell entre els anys 1941 i 1970 (en ombrejat es mostren els barris que estaven en construcció aquell any):

\section{L'explosió del desordre urbanístic periferic}

El primer cens de població de la nova periferia urbana de Sabadell dut a terme per la recent creada «Delegación de Suburbios» municipal de 1955 estima que 1.178 persones vivien en coves $i$ en barraques.

Aquest és també l'any que es crea el «Patronato Municipal de la Vivienda», amb l'objectiu de construir 3.000 nous habitatges en deu anys. Paral-lelament, la difusió suburbial inconnexa a la ciutat ja era un fet d'abast considerable des

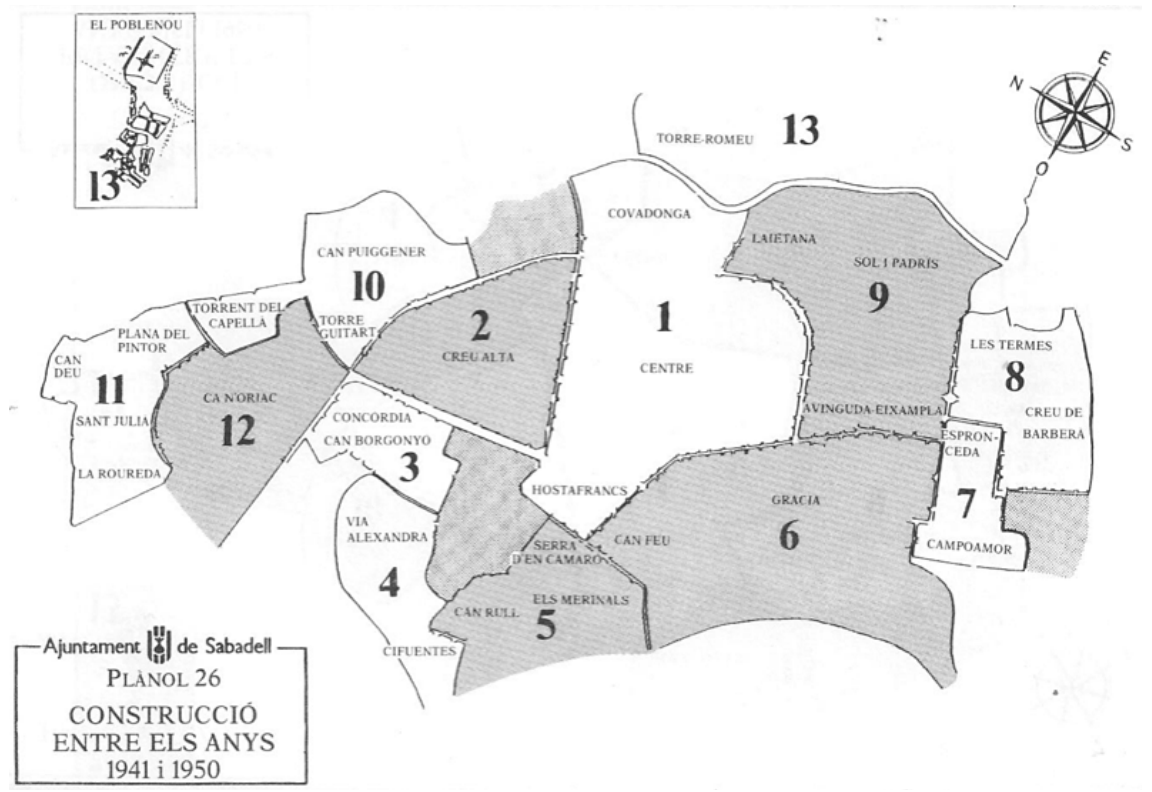

Figura 1. Plànol del terme municipal de Sabadell entre els anys 1941-1950.

Font: Alabart i Sapès, en La població i l'habitatge a Sabadell. Ajuntament de Sabadell, 1983. 


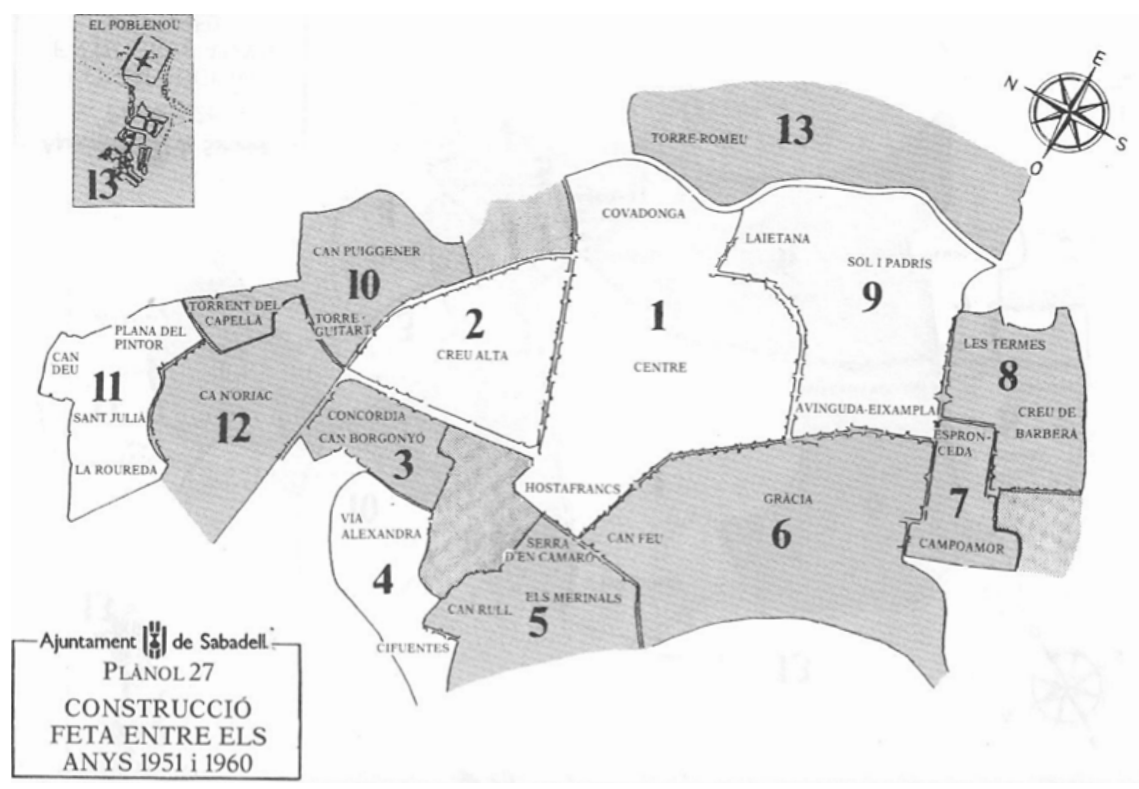

Figura 2. Plànol del terme municipal de Sabadell entre els anys 1951-1960.

Font: Alabart i Sapès, en La població i l'habitatge a Sabadell. Ajuntament de Sabadell, 1983.

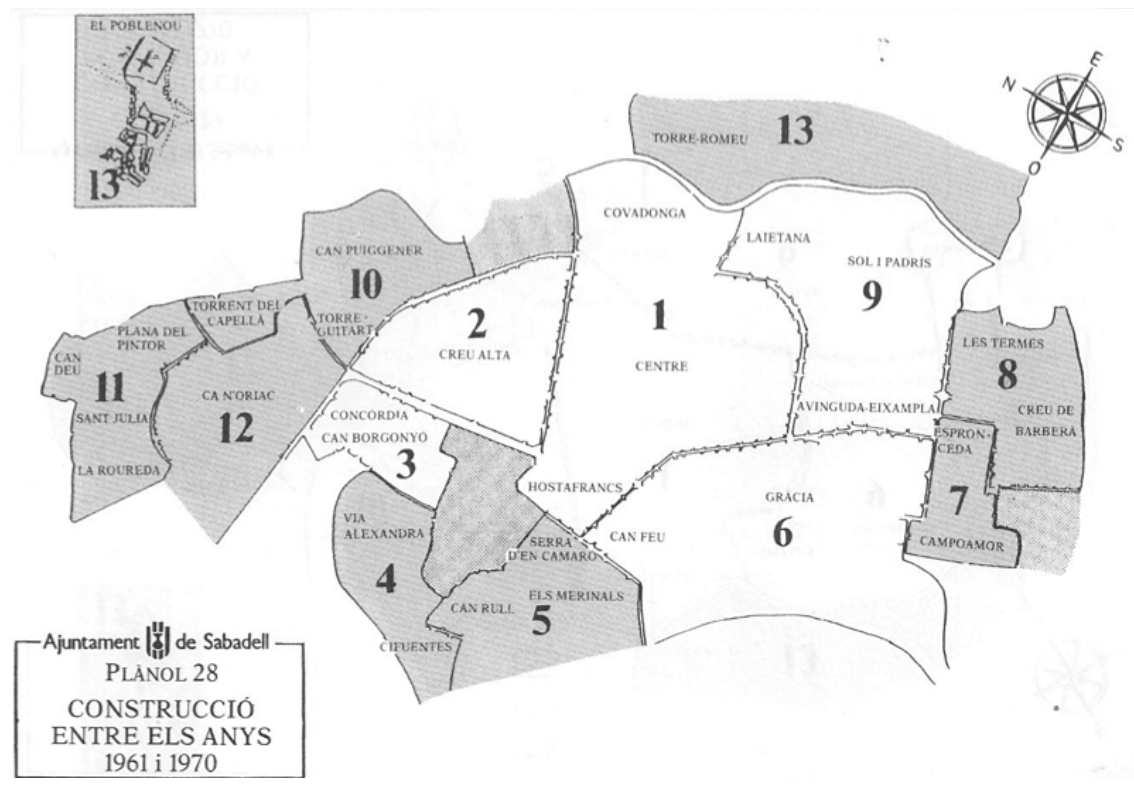

Figura 3. Plànol del terme municipal de Sabadell entre els anys 1961-1970.

Font: Alabart i Sapès, en La població i l'habitatge a Sabadell. Ajuntament de Sabadell, 1983. 
de l'any 1951, en què es té constància de la venda de parcel.les al comptat i a terminis a través d'empreses i de particulars de terrenys no urbanitzables, els quals podien ser preferibles davant del fet de residir en una zona altament densificada. Arran de la impossibilitat de complir el pla anterior, l'Ajuntament promou la donació per compte de l'erari municipal de materials per a la construcció a tot aquell que presenti un contracte de compra de terrenys, generalment a terminis, sense previ pla d'emplaçament i sense cap mena de projecte tècnic.

Les conseqüències d'aquesta política no triguen a manifestar-se: deficiències constructives, precarietat sanitària, densificació, separació envers el nucli urbà, etc. En definitiva, uns suburbis que, com va definir Manuel Ribas Piera (1968), representen el viu reflex de la no-ciutat, tal com es fa també palès en el conegut estudi sobre les barraques de Barcelona (La Ciutat Informal, 2008). A més, aquestes deficiències es donen en una ciutat com Sabadell, on a partir de 1960 el cens d'obrers industrials respecte al nombre de població total és del 40\%, el doble del que, aleshores, té Barcelona (Moragas, 1962).

Tot seguit ens ocupem de la relació entre la renda obrera d'aquells anys i la tipologia de l'habitatge al qual s'accedeix.

\section{Nivell de renda i habitatge obrer (1940-1960)}

El baix nivell d'ingressos, que afectava un 90\% de la població treballadora de Sabadell, especialment la immigrant (Cedec, 1965, 169) impedeix disposar de recursos per adquirir habitatge, ja sigui de propietat o de lloguer. Es pot estimar que la despesa en lloguer representava l'11\% de la despesa total d'una família de quatre membres de l'any 1961 (Asociación Católica de Dirigentes de Sabadell, 1962).

Amb motiu dels baixos salaris, gairebé un 10\% del total de la població de Sabadell havia de rebre assistència benèfica l'any 1960. Aquestes ajudes les perceben majoritàriament els residents en els suburbis obrers i les pensions i estades del nucli urbà (Obradors, 1962). En aquest sentit, s'ha de recordar la forta regressió patida pels salaris reals a Espanya entre el 1939 i el 1957, que s'uneix a l'augment de les jornades laborals. A Sabadell, durant aquest període, els salaris reals només arriben a cobrir la despesa en alimentació, en la qual una família de quatre membres hi havia de dedicar el 71,08\% del pressupost familiar, mentre que al 1936 s'hi destinava el 53,35\%. (Boletín de la Asociación Católica de Dirigentes de Sabadell, 76, 1961).

Com mostra l'estudi sobre la beneficència a Sabadell, a càrrec de Montserrat Obradors, el 1961, un 69,09\% dels 977 habitants de les cases «ultrabarates» de Fàtima, al barri de Campoamor, han de ser assistits, fins i tot aquells que tenen famílies rellogades a casa seva. S'estima que en tan sols 34 cases viuen 93 famílies, on conviuen molts nens i malalts apinyats.

Els propietaris de les cases paguen els terminis de 150 pessetes mensuals durant quinze anys, mentre que els seus rellogats paguen, després d'abonar sovint una entrada de 12.000 pessetes, 600 pessetes de lloguer al mes. En una 
Taula 1. Tipologia d'habitatge i nombre de famílies residents a Sabadell el 1961

\begin{tabular}{lc}
\hline Tipologia d'habitatge & Nombre de famílies \\
\hline Rellogats il.legals & 71 \\
Estades & 174 \\
Pensions & 42 \\
Barraques & 41 \\
Coves & 1 \\
Recollits & 24 \\
Total & 353 \\
\hline
\end{tabular}

Font: M. Obradors, 1962. La beneficencia en Sabadell. Mecanografiat inèdit, 272.

d'aquestes cases hi poden arribar a viure 24 persones, que fan servir el mateix WC i safareigs (Obradors, 1966).

El 1961 el 9,39\% dels 105.951 habitants de Sabadell necessitava ajuda directa de la beneficència. Aquesta ajuda calia fins i tot fora dels suburbis, donada la sobreocupació provocada pels baixos salaris i el consegüent problema d'accessibilitat a l'habitatge, que repercuteix en el nucli de la ciutat estricta.

El 1961, segons dades oficials del municipi, hi havia, a més del dèficit per sobreocupació, 2.069 habitatges inhabitables en els suburbis.

L'habitatge més precari fou, juntament amb les coves i les barraques, el de les anomenades estades (Puig, 1987), existents abans de 1939 i posteriorment, un tipus d'habitatge similar als Passadissos de Collblanc-La Torrassa (Fernández de Retana, 1992). En aquestes, l'espai útil per a una família no superava els $20 \mathrm{~m}^{2}$. A les estades s'accedia als diversos habitatges per un passadís estret en una disposició d'habitacions (similar a les «ciudadelas» de Santa Cruz de Tenerife) i al final d'aquest es trobaven els serveis per a ús de tots els ocupants de cada habitatge. Si bé aquests tipus d'habitatge marginal s'implanta també molt en els suburbis, cal fer una referència especial a les estades de l'eixample de Sabadell que, degut a la seva proximitat a les fabriques, registren un fort índex d'ocupació.

Davant d'aquest panorama d'infrahabitatge, a continuació veurem com, a partir de 1955, la patronal local intentarà iniciar l'acció de construcció d'habitatge més ambiciosa fins aleshores portada a terme.

\section{L'activitat constructora de l'empresariat tèxtil sabadellenc}

Amb la llei del 12 de juliol de 1955 l'Estat modifica la de 1947, que obligava a construir habitatges a les empreses de nova creació que tinguessin més de 50 treballadors. Des d'aleshores, la nova llei exigeix a totes les empreses, siguin o no de nova creació, implicar-se en la construcció d'habitatges per as seus obrers.

Per tal de complir la legalitat, un grup d'industrials tèxtils adscrits al Gremi de Fabricants de Sabadell acordà constituir el 1956 una cooperativa de construcció d'habitatges populars (COVIPSA), que era gestionada pel Gremi de Fabricants de Sabadell. COVIPSA descarregava les empreses d'una activitat 
aliena al seu ram empresarial, a més de facilitar-los el compliment de la llei, la qual es proclamà també continuadora d'aquell Pla Marcet d'habitatges de 1952 que, en la pràctica, no havia assolit els seus objectius. COVIPSA aplegà de nou la Junta Ciudadana de Construcción de Viviendas, integrada per una bona part de les personalitats del Gremi de Fabricants de Sabadell, de la qual n'era hereva la nova cooperativa, com així es reflecteix en els seus estatuts fundacionals, legalitzats a la notaria de José Maria de Porcioles Colomer, concretament en el seu article I.

Que la grave situación que reviste el problema de la vivienda en la ciudad de Sabadell, no podía dejar indiferentes a los industriales de la misma agrupados en el Gremio de Fabricantes, entidad aglutinadora de las inquietudes y anhelos sociales de los mismos, en el seno de la cual se había estudiado en repetidas ocasiones, durante los últimos años, tal problema que por distintas circunstancias no puedieron plasmarse en el terreno práctico ${ }^{5}$

I és que si bé no s'expliciten els impediments per solucionar el problema de l'habitatge, des d'ara cal atendre la nova legislació, com es recull en l'article II:

El objeto social de la Compañía será única y exclusivamente la construcción de viviendas de renta limitada, en particular las que están obligados a edificar las Empresas por la orden conjunta de 12 de julio de 1955, su administración en renta y eventuales enajenaciones, todo ello con arreglo a la legislación especial aplicable y acogiéndose a los beneficios acordados en la misma.

La Cooperativa es va constituir amb un capital inicial de 3.000.000 de pessetes, representat per 600 accions al portador de 5.000 pessetes. El 1956 només desemborsà el 25\% del capital inicial; la resta, fins al 1964. Cada quatre accions subscrites equivalien a les 20.000 pessetes per cada habitatge que, afegides a les 30.000 de la subvenció estatal, més el préstec complementari, juntament amb l'entrega inicial, havien de cobrir el cost de cada habitatge adjudicat ${ }^{6}$.

Els anys 1957 i 1958, COVIPSA va adquirir els terrenys del passeig del Comerç amb la carretera de Barcelona per gairebé 2.211.580 pessetes ${ }^{7}$.

Per tal de portar a terme de manera immediata aquesta primera construcció a la Creu de Barberà, la qual constava de 198 habitatges, COVIPSA sol-licità l'abril de 1957, a l'encara Instituto Nacional de la Vivienda, la tramitació de la concessió de la subvenció legal.

La sol-licitud coincideix, però, amb el just moment que la legislació és modificada arran de la creació del Ministeri de l'Habitatge i la desaparició del règim de renda limitada pel d'habitatges subvencionats. Així, des de l'1 de febrer de 1958, l'obligació de les empreses de construir directament habitatges per als seus obrers passà a convertir-se en la de concedir-los préstecs.

5. Escritura fundacional. Estatutos de la Sociedad COVIPSA, 1956.

6. Memoria sobre la carga financiera de las empresas pertenecientes a Covipsa. 1-9-1960.

7. Escritura de compra-venta. 28-5-1957 y 18-9-1958. 
Amb tot, el projecte de construcció de COVIPSA s'hagué de replantejar d'acord amb la nova política d'habitatge estatal, que exigeix una edificació de tipus més reduïda. Aquest fet explica la pèrdua de gairebé tres anys per començar l'edificació, ja que el projecte inicial no era admissible i s'havia de replantejar. El nou projecte, ara per a 204 habitatges i quatre locals en els baixos, fou presentat per ser qualificat el gener de 1960, amb la previsió de poder començar les obres el segon trimestre d'aquell any ${ }^{8}$.

Tot i la reactivació de COVIPSA, el gener de 1961 moltes empreses que hi pertanyien encara no havien desemborsat les accions subscrites, tot i que es converteix en constructora d'habitatges per compte propi per vendre'ls al públic en general.

El primer grup d'habitatges del passeig del Comerç edificat per COVIPSA s'inaugurà el dia 26 de gener de 1962. L'entrada inicial era d'unes 30.000 pessetes amb una quota mensual durant vint anys de 400 i 500 pessetes, segons si es tractava d'un pis tipus A (es van construir 100 habitatges de $46 \mathrm{~m}^{2}$ útils) o tipus B (s'edificaren 104 habitatges de $61 \mathrm{~m}^{2}$ útils). El preu s'havia de pagar durant vint anys amb els interessos corresponents?

Les empreses de la cooperativa van col.laborar amb 30.000 pessetes per cada habitatge, i la Caixa d'Estalvis de Sabadell, amb les hipoteques que s'havien de retornar al cap de vint anys.

Cal esmentar que una vegada acabats els habitatges del grup Espronceda de COVIPSA, el 1962, no és fins al 1964 que s'inicien les gestions per asfaltar el passeig del Comerç.

L'altra iniciativa empresarial de construcció d'habitatges de renda limitada, en la seva modalitat de subvencionades, que atorga el Ministeri de l'Habitatge, va ser portada a terme per l'empresa Viviendas Sabadell, S.A. (Visasa), que va ser presidida inicialment per l'empresari tèxtil Rafael Soler, però ideada per l'aleshores president de l'Asociación Católica de Dirigentes (en endavant, ACD), Antoni Forrellad. Va ser creada l'any 1958 sense ànim de lucre, amb la voluntat manifesta de contribuir a la solució del problema de l'habitatge. Visasa es constituí amb un capital social de 10 milions de pessetes, dels quals se'n desemborsaren 6 milions. Cáritas de Madrid subscrigué el 25\% d'aquest capital (Monés, 1996).

La societat estava plenament vinculada a l'ACD, entitat patronal catòlica amb seu a Barcelona i delegació a Sabadell. Aquesta societat estava guiada per una voluntat europeista, moguda per una certa por al comunisme, i per això oferia la voluntat d'obrir la participació dels obrers a les societats anònimes, per fomentar el capitalisme popular, per tal d'estendre la petita propietat a la classe treballadora, establir una fiscalitat justa, reduir les diferències de salaris entre homes i dones, i alhora fomentar l'estalvi popular. Aquest estalvi, en el cas de l'habitatge, es concretava en el foment de la cultura de la propietat.

8. COVIPSA. Memoria de 1964.

9. COVIPSA. Acta de 16-1-1962. 
Aquest grup empresarial integrat a Visasa endegà els seus primers 520 habitatges a la Concòrdia, els anys 1960 i 1961, al mateix temps que havia impulsat a la ciutat una sèrie de conferències públiques amb personatges del catolicisme social de més relleu de Catalunya, per tal d'establir la xifra d'un salari mínim vital, donat que moltes empreses de Sabadell no el pagaven ${ }^{10}$.

Els pisos de l'anomenat sector Concòrdia, de $80 \mathrm{~m}^{2}$ útils, foren venuts per 60.000 pessetes. Encara que el seu cost era de 90.000 , amb les 30.000 donades a fons perdut per l'Estat, quedaven per 60.000 pessetes, que s'havien de pagar durant vint anys mitjançant una hipoteca contreta amb la CES al 6\% d'interès, que representava una quota mensual de 340 pessetes.

Aquesta activitat constructora, basada en el foment de la cultura de l'habitatge de propietat fins al 1961, en arribar l'aiguat de setembre de 1962, es va mostrar del tot insuficient i ineficaç per proveir d'habitatges la població de renda obrera.

\section{Habitatge, pobresa i desastre: unes relacions amagades?}

De fet, desastre i pobresa es troben relacionats en el cas dels aiguats de Sabadell i del seu suburbi de Los Rosales, al terme de Sant Quirze del Vallès, el setembre de 1962.

El nombre de famílies damnificades quantificades va ser de 221, però aquesta riuada deixà el terreny abonat perquè els aiguats i les riuades dels dies 4, 5 i 6 de novembre, encara que no causaren cap mort, deixessin una xifra de damnificats que sovint passa desapercebuda però que arribà a les 652 famílies. Els habitatges que resultaren afectats a Sabadell i que quedaren inhabitables superaven la xifra de 400 en total (Cedec, 1965).

Pel que fa a les indemnitzacions a les famílies damnificades per pèrdues humanes i dels habitatges i els estris, les quantitats rebudes estaven per sota dels valors declarats. Començava així un llarg periple de reclamacions davant l'administració provincial.

Com hem dit, a Sabadell les riuades, a més de causar la mort de 33 persones, deixaren finalment 400 habitatges destruïts.

Algunes de les víctimes que treballaven en el torn de nit de les fabriques a la llera del riu van deixar famílies desemparades que depenien d'una sola persona que, a la pràctica, els feia de cap de família i que, a més, residien en estades o en habitacles precaris autoconstruïts.

Els damnificats no reberen la visita de cap personalitat política rellevant, llevat de la de Franco, acompanyat pels empresaris tèxtils a les fabriques afectades del riu Ripoll.

El mes de novembre, l'Ajuntament de Sabadell es va veure abocat a exigir als propietaris de cases deshabitades la seva cessió temporal per allotjar-hi famílies damnificades. La petició municipal de cessió d'habitatges per a aquesta finalitat s'havia fet des d'un primer moment, però el nombre d'habitatges cedits

10. Boletín de la Asociación Católica de Dirigentes de Sabadell, 76, 1961. 
va ser insuficient. Per aquest motiu, el mes de novembre, amb el segon episodi dels aiguats, l'Ajuntament admet denúncies que informen de l'existència de cases deshabitades a la ciutat sota l'apercebiment de sanció. El cens municipal d'habitatges de 1960 — en plena escassetat d'habitatge obrer- donava la considerable xifra de 1.070 habitatges buits.

A Sabadell, després de les riuades de setembre i de novembre, el parc d'habitatges insalubres i sobreocupats va quedar molt malmès, per la qual cosa va augmentar el dèficit crònic d'habitatges que patia la ciutat, principalment en els suburbis sobrepoblats. Això fa renéixer entre la classe empresarial tèxtil de la ciutat la necessitat de reemprendre la tasca constructora a partir de la compra de nous terrenys, tasca que havia quedat interrompuda des de 1961.

Per als damnificats residents en habitatges insalubres i sobresaturats només quedava l'esperança d'obtenir un dels pisos que l'Obra Sindical del Hogar construí al barri de Campoamor, en el polígon Espronceda, inaugurats el desembre de 1963, amb motiu de la riuada.

$\mathrm{Al}$ mateix temps, les obres d'encasament i drenatge del riu s'anaven ultimant i la indústria de Sabadell i de Terrassa rebia un suculent préstec de 1.000 milions avalat per la Diputació de Barcelona, que s'havien de pagar en vuit anys a un mòdic interès del 3,5\%, el qual encara avui no s'ha acabat de retornar del tot. Aquest préstec va permetre renovar la maquinària i l'utillatge d'un sector tèxtil a punt de començar el seu declivi en l'hegemonia industrial de la ciutat al 1964.

D'ençà la visita de Franco els anys 1962 i 1963, acollit fervorosament per l'empresariat local a la fabrica Grau, o la que se li dispensà en olor de multituds a un polígon Espronceda a punt de ser acabat i que fou qualificat en el seu moment com «erigido con los más avanzados medios técnicos», el Caudillo esdevé a Sabadell gairebé un mite.

Com hem dit, la promoció accelerada d'habitatges per als damnificats tingué lloc en l'anomenat polígon Espronceda, al sud de Sabadell, construït amb materials prefabricats de mala qualitat que presentarà problemes immediatament i durant molts anys per als seus habitants. Aquests problemes no es podran resoldre fins ben entrada la democràcia.

Així doncs, els aiguats van repercutir en les condicions dels habitatges dels suburbis, i van agreujar encara més la problemàtica. El que també es va considerar preocupant és que els aiguats van contribuir a donar a conèixer a l'exterior la magnitud de l'existència d'habitatge precari d'una ciutat industrial com Sabadell, exportadora a escala internacional.

Aquesta darrera qüestió és, principalment, la que portarà immediatament després dels aiguats que el Gremi de Fabricants de Sabadell plantegi un pla urgent per construir 5.000 habitatges. El pla reconeix que malgrat que s'han construït «milers» d'habitatges des de COVIPSA, Visasa i el Patronat Municipal de l'Habitatge, emparats amb els crèdits de la CES, el dèficit acceptat per les institucions econòmiques i empresarials de la ciutat es quantifica en 7.000 habitatges a finals de 1962 (Cedec, 1965). Així, el dèficit d'habitatges de 1960, establert en 5.200, va passar a finals de 1962 a 7.000, per l'increment de la immigració d'aquests dos anys i per l'efecte de les riuades. 
El pla de construcció d'habitatges impulsat des del Gremi de Fabricants passà per cobrir la major part d'aquest dèficit a partir de l'anomenat Plan para la construcción de cinco mil viviendas en Sabadell (Gremi de Fabricants de Sabadell, 1963). La resta del dèficit fins a 7.000 es preveia cobrir quan s'acabessin els 500 habitatges que va construir Visasa en aquell moment a Les Termes, juntament amb les 2.000 que estava construint l'Obra Sindical del Hogar en els polígons de San Bernardo i Espronceda.

La previsió del Gremi de Fabricants parteix de la voluntat d'impulsar una acció coordinada entre el Patronat Municipal de l'Habitatge, COVIPSA i Visasa per edificar en el futur el nombre d'habitatges necessaris de renda limitada subvencionats, davant l'augment de població dels anys venidors.

El primer pas per portar a terme el pla no va venir fins al 1964, quan COVIPSA va comprar els terrenys de la Gran Via de circumval.lació de Collsalarca, davant de l'alberg del Nen Jesús, propietat de la CES. Aquell mateix any COVIPSA demanà al Ministeri de l'Habitatge la qualificació d'habitatges subvencionats per a la promoció, el qual va canviar de política i va fer impossible acollir-s'hi. Per això es van haver de construir com a lliures, amb el consegüent augment de les despeses d'edificació per a la promotora.

Aquest fet va retardar l'inici de les obres, que s'executaren en quatre fases. La promoció va constar de sis blocs de tres edificis independents cadascun, amb pisos de tres i quatre habitacions, amb un total de 708 habitatges de $63 \mathrm{~m}^{2}$ útils.

Per obtenir el finançament necessari per a l'adquisició dels pisos, les empreses concedien un préstec de 40.000 pessetes a COVIPSA, que retornava en cobrar les assignacions del Ministeri de l'Habitatge, que s'havien de tornar en vint anys al 3\% (a banda, l'empresa gaudia de desgravacions fiscals per aquest motiu), més un altre préstec de COVIPSA de 23.000 pessetes, i part d'aquest préstec de la Caixa d'Estalvis de Sabadell que s'havia de retornar en vint anys. El 50\% del preu total del pis s'ajorna a quinze anys. El preu de cada pis s'estipulà en unes 253.000 pessetes. Els primers pisos es començaran a adjudicar als treballadors de les empreses tèxtils o de monts de pietat metal.lúrgics que, en alguns casos, havien resultat damnificats en les riuades de 1962 durant els anys 1969 i 1970. Durant aquest temps, però, van continuar residint en els suburbis massificats, en habitatges insalubres autoconstruits.

El nou pis per al treballador li representarà pagar una quota mensual d'entre 1.600 i 1.800 pessetes mensuals durant quinze o vint anys ${ }^{11}$.

Tanmateix, per la seva part, Visasa ultimà la promoció d'habitatges de Les Termes i inicià l'any 1969 la promoció de pisos a Can Puiggener ${ }^{12}$.

Així doncs, la situació de dèficit d'habitatge i de suburbis, «informes» com se'ls denominava a l'època, agreujats pels efectes dels forts aiguats de 1962, sobretot aquells que n'havien resultat damnificats, hagueren d'esperar gairebé més de vuit anys per millorar la seva situació de vulnerabilitat arran de la seva condició sociolaboral.

11. COVIPSA, carta a las empresas agremiadas, Sabadell, 1964.

12. AHS. Llicències municipals, 1969. Exp. 02734. 


\section{Conclusions}

Malgrat la seva gran magnitud, no es pot afirmar que els aiguats de 1962 fossin un episodi meteorològic realment únic en l'àmbit de la Mediterrània i del Vallès, ja que les pluges abundants formen part del clima d'aquestes contrades i sobretot la perillositat a les lleres de la xarxa hidrològica pel relleu del massís de Sant Llorenç del Munt.

Així, cal anar sobretot al component humà a fi d'explicar la tragèdia. Una primera conclusió la podem establir en la línia que els efectes dels episodis dels aiguats de 1962 es podien haver minimitzat si no s'hagués consentit l'ocupació de les lleres dels rius i les rieres per a habitatges i fabriques. A més de no haverse instaurat l'autoconstrucció en terrenys no edificables.

En el cas de Sabadell, l'edificació en terrenys no urbanitzables fou estimulada per l'administració local al llarg del període comprès entre 1940 i 1963. Aquesta política urbanística la seguiren les autoritats polítiques del franquisme, d'acord amb l'especulació urbanística del moment. A la vegada, projectaven fora de la ciutat uns immigrats que en un primer moment foren vistos com un problema i, per això, desplaçats a uns suburbis segregats socialment i urbanísticament de la ciutat.

Del problema de la immigració com un recurs imprescindible, es passà al problema dels suburbis d'habitatge autoconstruits amb materials facilitats pel mateix municipi, sempre que s'acredités la compra d'un terreny sovint no urbanitzable.

S'ha de tenir en compte que els damnificats de les riuades foren majoritàriament població immigrada pobra, el nivell de salaris de la qual estava per sota del salari mínim vital reconegut públicament per la mateixa ACD de Sabadell.

Una segona conclusió es desprèn de la consulta dels expedients dels damnificats tramitats per la junta distribuïdora de fons de la subscripció nacional de 1962 prodamnificats del Vallès, per al cas de Sabadell juntament amb el de Los Rosales. A cada expedient, les notes de l'interventor són prou eloqüents quan expressen la dramàtica situació econòmica i social, amb anotacions com aquestes: "Han perdido muy poco porque no tenían casi nada». Aquest gairebé res no fou sovint indemnitzat per la quantitat declarada.

La gestió i el reconeixement de les indemnitzacions per als damnificats fou molt deficient $\mathrm{i}$ injusta en molts dels casos, la qual cosa no deixa de ser un greuge comparatiu amb el famós crèdit acordat pel Consell de Ministres el dia 1 d'octubre de 1962 a la indústria tèxtil de Sabadell i de Terrassa per 1.000 milions de pessetes a través del Banc d'Espanya a baix interès - del 3,5\% al 4,25\%-, que s'havia de pagar en vuit anys i que encara no s'ha retornat totalment a dia d'avui.

La tercera conclusió a la qual podem arribar és que, tant a Sabadell com a la resta de les principals ciutats industrials del país, com per exemple Barcelona, es passa del règim de lloguer, on arribava fins al 95\% l'any 1950, a partir de la congelació d'arrendaments i la consegüent desmotivació dels inversors 
en el negoci, cap al règim de tinença en propietat. Afavorit sens dubte per la necessitat d'habitatge de la població nouvinguda ${ }^{13}$. Aquest procés de canvi en la tinença de l'habitatge es veié afavorit per la venda de terrenys no urbanitzables que més tard, el 1962, són reconeguts legalment com a urbans. A la vegada, el paternalisme franquista i els poders econòmics de Sabadell, d'acord amb la legalitat vigent, obren pas al negoci immobiliari mitjançant l'adjudicació a la iniciativa privada de la concessió d'importants subvencions, elevades exempcions tributàries i desgravacions fiscals, com és el cas de COVIPSA o Visasa, ambdues centrades en la construcció d'habitatges per als treballadors. Cal significar, però, que l'especulació urbanística la dugueren a terme en aquests anys principalment els propietaris de sòl de Sabadell.

$\mathrm{El}$ pas cap al règim de propietat serà, doncs, resultat del negoci de la requalificació de terrenys que tingué lloc a Sabadell a partir de 1962, gràcies a la vulneració de les previsions del Pla Provincial d'Urbanisme d'aquells anys, que va impulsar així el «boom immobiliari» fins a 1973. Com hem vist, negoci immobiliari i control social són els principals arguments que expliquen aquest canvi de règim de tinença de l'habitatge. En aquest sentit, podem concloure que l'incident meteorològic de 1962 fou aprofitat per legitimar encara més el discurs desarrollista del sòl i per a la dominació de la tinença d'habitatge en propietat davant del lloguer.

D'acord amb Naredo (2010), la promoció d'habitatge de propietat es donà a partir de la política d'habitatge iniciada pel franquisme de 1940 a 1970 i que culminà l'any 2007. Malgrat tot, amb una diferència: des de 1973, es posà fi a la promoció pública de lloguers assequibles o de propietat «ultrabarata» de l'etapa del paternalisme franquista.

Els mecanismes d'urbanització especulativa de Sabadell, com els que han tingut lloc a la resta del país, han conduït a ser els darrers en construcció d'habitatge protegit de tot Europa.

Els problemes d'habitatge del període 1940-1970 s'han tornat a repetir en l'actualitat, amb l'aparició de barraquisme, infrahabitatge i de rellogats; però a diferència de l'etapa estudiada, la situació actual es produeix comptant amb un gran parc d'habitatges sobredimensionat de propietat, al qual la majoria de la població no pot accedir per l'elevat preu i per l'elevada taxa d'atur. La situació es pot constatar en els barris de nova creació de la ciutat vallesana. Sabadell arriba a aquesta situació perquè la ciutat també és hereva del seu passat. I cal recordar que ara, com al 1962, ens movem en un període que es torna a caracteritzar per la regressió dels salaris i el deteriorament de les condicions de treball.

Finalment, en el procés cap al model esmentat, les riuades que donaren lloc a la catàstrofe humana de 1962 al Vallès van ser aprofitades per endegar

13. Com bé assenyala Xavier Tafunell, 1989, la política de congelació de lloguers afavorí majoritàriament els contractes de llogaters d'abans de 1940, mentre que tingué un efecte negatiu per als nous llogaters i favorable per a l'especulació urbanística; això seria així a partir de la Llei de lloguers de desembre de 1946. 
els mecanismes especulatius que han portat al model urbà actual de caràcter suburbial dins el conjunt de la conurbació de Barcelona. A la vegada, van marcar l'inici de l'especialització en el negoci immobiliari en detriment de l'activitat industrial de Sabadell.

\section{Referències bibliogràfiques}

Alabart, Anna i Sapés, Jordi (1983). La població i l'habitatge a Sabadell. Ajuntament de Sabadell.

Asociación Católica de Dirigentes de Sabadell (1961). «El desequilibrio estructural, causa básica del suburbio». Asociación Católica de Dirigentes, 65, 1-2.

- (1962). Son justos los salarios que perciben nuestros obreros. Sabadell.

Bevere, Lucia i Enz, Rudolf (2012). Natural catastrophes and man-made disasters in 2011: historic losses surface form record earthquakes and floods. Swiss Reinsurance Company Ltd.

BORRI, Maria Teresa (1964). Vida sociocultural y su correlación con la religiosa en la Creu de Barbarà de Sabadell. Estudi mecanografiat inèdit.

Casañas, Joan (2010). L'aportació de Càritas a Sabadell 50 anys. Sabadell. Càritas.

CEDEC (1965). Sabadell, déficit de viviendas. Sabadell. Ciclostilat.

Cotorruelo, Agustín (1960). La politica económica de la vivienda en España. Madrid: Consejo Superior de Investigaciones Científicas. Instituto Sancho de Moncada.

Delegación de los Servicios Hidráulicos del Pirineo Oriental. Estudios, proyectos y obras realizadas hasta $1^{\circ}$ de marzo de 1937. Exposición de obras públicas en Valencia. Marzo de 1937.

Duocastella, Rogeli (1962). Planificación de servicios sociales de la ciudad de Sabadell (Barcelona). Sabadell. Ciclostilat.

Farrés, Jesús (1961). «El creixement de la població». Alba. 137, 246-247.

Fernandez de Retana, (1992). «Els passadissos de Collblanc-La Torrassa 1900-29. L'essència d'un barri dormitori». Revista Catalana de Geografia, 17 (VI), 51-60.

Foriscot, A. P. (1963). «Sobre el Vallés se abatieron 2.688.562.500 metros cúbicos de agua». La Vanguardia Española, 14 de agosto, 6.

GAjA, Fernando (2007). «¿Corrupción urbanística o currupción del urbanismo?» $<$ http://www.levante-emv.com/opinion/3403/corrupcion-urbanistica-o-corrupcion-urbanismo/263378.html> Levante-emv.com [consulta: 6 de juny de 2012].

J. B. (1962). «Informe sobre les inundacions de setembre». Serra d'Or, 11. Any IV.

Magriña, Anna Maria (1964). El barrio de Los Rosales de San Quirico de Terrassa. Victima de las inundaciones de 1962. Estudi mecanografiat inèdit.

MarCET, José María (1952). El problema de la vivienda en Sabadell. Imprenta Linograf.

Masjuan, Eduard (2006). Medis obrers i innovació cultural a Sabadell (1900-1939). Universitat Autònoma de Barcelona.

Masjuan, Eduard (2010). «Les coves de Sant Oleguer. La periferia de la ciutat industrial durant el franquisme». $<$ http://ca.sabadell.cat/Coves/d/immigracio.pdf $>$.

Masjuan, Eduard, March, Hug i Saurí, David (2011). «Flujos de capital y flujos de agua: la industria téxtil y la privatización del suministro de agua en la Ciudad de Sabadell durante la segunda mitad del siglo Xx». Boletín de la Asociación de Geógrafos Españoles, 56, 245-261.

Monés, Antoni (1996). Pels camins de la memòria. Fundació Amics de les Arts i de les Lletres de Sabadell. 
Moragas, Emilio (1962). Influencia del Plan General de Ordenación de la Provincia de Barcelona en el desarrollo de la ciudad de Sabadell. Sabadell: Cuadernos de Archivo de la Fundación Bosch y Cardellach, 5. (1965). A l'entorn de l'estudi sobre planificació de serveis socials a Sabadell. Sabadell: Cuadernos de Archivo de la Fundación Bosch y Cardellach, 10.

Naredo, José Manuel (2010). El modelo inmobiliario español y sus consecuencias. <http://habitat.aq.upm.es/boletin/n44/ajnar.html>.

Obradors, Carmen (1966). La integración del suburbio en la comunidad urbana. Editorial Nova Terra.

Obradors, Montserrat (1962). La beneficiencia en Sabadell. Mecanografiat inèdit.

Puig, Jaume (1987). L'evolució tipològica de l'habitatge de Sabadell. Caixa de Sabadell.

Ribas, Manuel, (1968). "La immigració i la planificació urbanística». A: La immigració a Catalunya. Barcelona. Edició de Materials, 133-144.

Sabadell, (1952). «Semana Santa en las Cuevas de San Olegario». Sabadell. Año 11, 5.

TAFUnell, Xavier, (1989). "La indústria. La construcció: una gran indústria i un gran negoci» A: Nadal, Jordi, Maluquer de Motes, Jordi, Sudrià, Carles i Cabana, Francesc (eds.). Història econòmica de la Catalunya contemporània. Editorial Enciclopèdia Catalana, 6, 211-241.

VAlls, Jaume (2012). La riuada de 1962. La catàstrofe que sacsejà la Terrassa invertebrada del franquisme. Ajuntament de Terrassa.

Vandellós, Josep A. (1985). Catalunya, poble decadent. Edicions 62.

Pàgines web

Museu d'Història de Barcelona. Barraques, la Ciutat Informal. <http://www.barraques.cat> [consulta: 20 de gener de 2009]. 